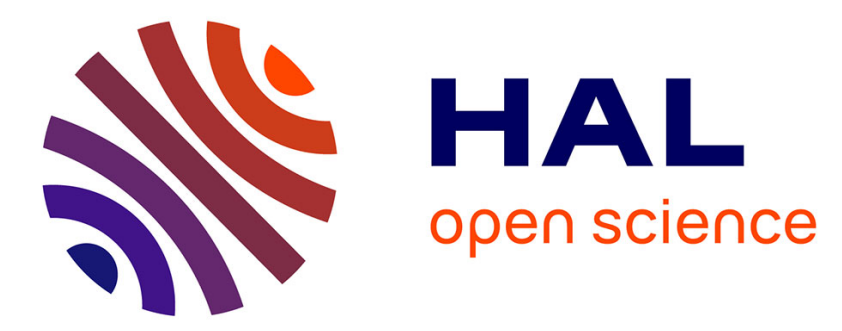

\title{
Selective photoisomerisation of 2-chloromalonaldehyde
} Alejandro Gutiérrez-Quintanilla, Michèle Chevalier, Rasa Platakyte, Justinas Ceponkus, Claudine Crépin

\section{To cite this version:}

Alejandro Gutiérrez-Quintanilla, Michèle Chevalier, Rasa Platakyte, Justinas Ceponkus, Claudine Crépin. Selective photoisomerisation of 2-chloromalonaldehyde. Journal of Chemical Physics, 2019, 150 (3), pp.034305. 10.1063/1.5082916 . hal-02328714

\section{HAL Id: hal-02328714 https://hal.science/hal-02328714}

Submitted on 23 Oct 2019

HAL is a multi-disciplinary open access archive for the deposit and dissemination of scientific research documents, whether they are published or not. The documents may come from teaching and research institutions in France or abroad, or from public or private research centers.
L'archive ouverte pluridisciplinaire HAL, est destinée au dépôt et à la diffusion de documents scientifiques de niveau recherche, publiés ou non, émanant des établissements d'enseignement et de recherche français ou étrangers, des laboratoires publics ou privés. 


\section{Selective photoisomerisation of 2- chloromalonaldehyde}

Cite as: J. Chem. Phys. 150, 034305 (2019); https://doi.org/10.1063/1.5082916

Submitted: 26 November 2018 . Accepted: 30 December 2018 . Published Online: 18 January 2019

Alejandro Gutiérrez-Quintanilla, Michèle Chevalier, Rasa Platakyte, Justinas Ceponkus, and Claudine Crépin (iD)

\section{PHYSICS TODAY} WHITEPAPERS
ADVANCED LIGHT CURE ADHESIVES

Take a closer look at what these

environmentally friendly adhesive systems can do 


\title{
Selective photoisomerisation of 2-chloromalonaldehyde
}

\author{
Cite as: J. Chem. Phys. 150, 034305 (2019); doi: 10.1063/1.5082916 \\ Submitted: 26 November 2018 - Accepted: 30 December 2018 • \\ Published Online: 18 January 2019
}

\begin{abstract}
Alejandro Gutiérrez-Quintanilla, ${ }^{1,2}$ Michèle Chevalier, ${ }^{1}$ Rasa Platakyte, ${ }^{1,3}$ Justinas Ceponkus, ${ }^{3}$ and Claudine Crépin ${ }^{1, a}$

AFFILIATIONS

${ }^{1}$ Institut des Sciences Moléculaires d'Orsay (ISMO), UMR 8214, CNRS, Université Paris- Sud, Université Paris-Saclay, F-91405 Orsay, France

${ }^{2}$ Instituto Superior de Tecnologías y Ciencias Aplicadas (InSTEC), Universidad de La Habana, Ave. Salvador Allende No. 1110, Quinta de los Molinos, La Habana 10400, Cuba

${ }^{3}$ Institute of Chemical Physics, Vilnius University, Sauletekio ave. 9 bat. III, L-10222 Vilnius, Lithuania
\end{abstract}

a) Author to whom correspondence should be addressed: claudine.crepin-gilbert@u-psud.fr

\begin{abstract}
Isomerization of 2-chloromalonaldehyde (2-ClMA) is explored giving access to new experimental data on this derivative of malonaldehyde, not yet studied much. Experiments were performed isolating 2-ClMA in argon, neon, and para-hydrogen matrices. UV irradiation of the matrix samples induced isomerization to three open enolic forms including two previously observed along with the closed enolic form after deposition. IR spectra of these specific conformers were recorded, and a clear assignment of the observed bands was obtained with the assistance of theoretical calculations. UV spectra of the samples were measured, showing a blue shift of the $\pi^{*} \leftarrow \pi$ absorption with the opening of the internal hydrogen bond of the most stable enol form. Specific sequences of UV irradiation at different wavelengths allowed us to obtain samples containing only one enol conformer. The formation of conformers is discussed. The observed selectivity of the process among the enol forms is analyzed.
\end{abstract}

Published under license by AIP Publishing. https://oi.org/10.1063/1.5082916

\section{INTRODUCTION}

2-Chloromalonaldehyde (2-CIMA) is a derivative of malonaldehyde (MA), the prototype of the $\beta$-dialdehyde family. MA has been extensively studied because its enol tautomer is the simplest molecule exhibiting a strong intramolecular hydrogen bond (IHB) with $\mathrm{H}$ exchanging between two oxygen atoms. In molecules belonging to this family, the dialdehyde form coexists with the enol one, but the latter is the most stable tautomer in the gas phase thanks to a resonant assisted hydrogen bond (RAHB). Most of the studies on MA, and especially theoretical studies, focus on properties related to the strong IHB: proton transfer and tunneling splitting of its vibrational levels (see, for example, Refs. 1-5 and references therein). MA is also a model molecule for excited-state intramolecular proton transfer (ESIPT). ${ }^{6-11}$ Few theoretical studies describe the effects of halogenated substituents on the RAHB and on the proton transfer, ${ }^{12-17}$ but there is a lack of experimental data on these MA derivatives.

We have recently explored the chelated enol form of 2-chloromalonaldehyde (2-ClMA), depicted in Fig. 1, in a matrix isolation study. ${ }^{18}$ This chlorinated derivative was characterized by means of its infrared (IR) and Raman spectra. The results confirmed a lowering of the IHB strength in 2-ClMA compared to MA, as theoretically predicted. Vibrational spectra of MA exhibit tunneling splitting of the vibrational levels in the gas phase, ${ }^{19-23}$ but the tunneling process is quenched in rare gas matrices. ${ }^{24-27}$ By contrast, we observed double bands for specific vibrational modes of 2-ClMA in Ar, assigned to a tunneling splitting in this matrix. ${ }^{18}$ Doublets also appear in para-hydrogen matrices, but not in neon matrices. There is an obvious matrix effect on the tunneling process. 


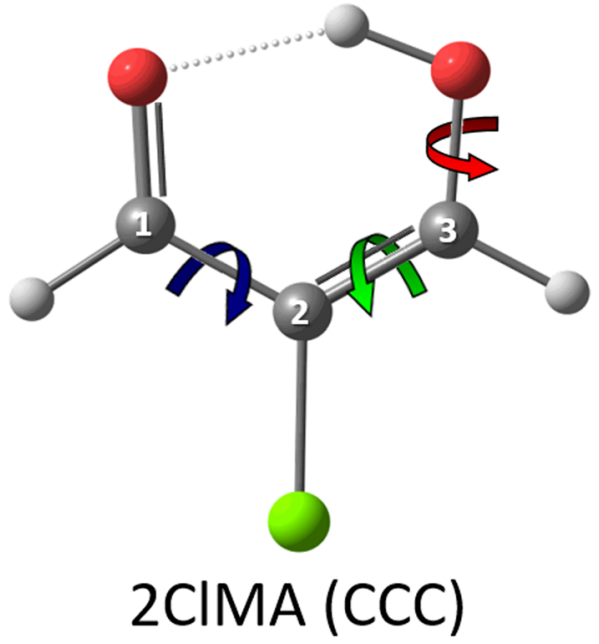

FIG. 1. cis enol tautomer (CCC) of 2-chloromalonaldehyde (2-CIMA). The carbon atoms are labelled from one (left) to three (right). The three rotations giving the $\mathrm{XYZ}$ conformers $(\mathrm{X}, \mathrm{Y}, \mathrm{Z}=\mathrm{C}$ or $\mathrm{T})$ are shown by arrows.

Another important result was the detection of traces of open enolic conformers (without IHB) in the spectrum of 2-CIMA after deposition of the cryogenic sample, whilst only the chelated enol conformer was detected in the case of MA under similar experimental conditions. The chlorine atom should therefore modify the relative energies of these conformers. Theoretically, there are eight enol conformers of MA (the same with 2-ClMA), called XYZ with $\mathrm{X}, \mathrm{Y}, \mathrm{Z}=\mathrm{C}$ for cis or $\mathrm{T}$ for trans, obtained by $180^{\circ}$ rotation around the $\mathrm{C}_{1}-\mathrm{C}_{2}$, $\mathrm{C}_{2}-\mathrm{C}_{3}$, or / and $\mathrm{C}_{3}-\mathrm{O}$ bond, respectively (see labels in Fig. 1). Some of the MA open conformers have been observed in different cryogenic matrices, following UV irradiation of the samples. ${ }^{24,26,28,29}$ UV photoisomerization in matrices was also extensively studied in the case of the closely related molecule: acetylacetone (AcAc). ${ }^{30-34} \mathrm{AcAc}$ is the simplest $\beta$-diketone obtained by exchanging the hydrogen atoms linked to carbons 1 and 3 in MA (see Fig. 1) by methyl groups. Because of steric effects, the relative energy of TTZ conformers compared to the chelated enol (CCC) is much higher in AcAc than in MA and the observation of these conformers is difficult. ${ }^{28}$ Moreover, a strong matrix effect was observed in the case of AcAc on the photoisomerization process with the production of different conformers depending on the matrix host. $31,33,34$

The present study based on the UV isomerization of 2-ClMA in matrices aims at the characterization of its nonchelated conformers and of the isomerization process. What is the effect of chlorination on the relative energies of open conformers? Are there matrix effects on these conformers, as observed for the CCC form? Are there matrix effects on the conformer production, as observed for AcAc? The experiments provided UV and IR absorption spectra of various enol conformers. Theoretical calculations helped to assign experimental bands to normal vibrations of 2-ClMA. The use of a tunable UV laser to induce the isomerization process allowed a selective production of conformers. All these results are discussed, with a peculiar attention to the comparison with MA and AcAc.

\section{METHODS}

\section{A. Theoretical calculations}

The Gaussian 09 (revision A.02) program $^{35}$ was used for all computations. Geometry optimizations were performed for all isomers (dialdehyde and enol forms) of 2CIMA, followed by frequency calculations, at the Density Functional Theory (DFT) level of theory with the Becke, 3 parameters, Lee, Yang and Parr (B3LYP) functional ${ }^{36,37}$ and 6-311++G(3df,3pd) basis set. A very tight convergence criterion for optimization and a superfine integration grid were applied. Vibrational frequencies were obtained by means of harmonic and anharmonic approaches. These computations allow calculations of Zero-Point Energies (ZPEs) for all the structures. A scaling factor of 0.976 was used in the presented harmonic spectra, except in the $\mathrm{OH}$ stretching range. We have carried out least-squares linear fits of the experimental (in para-hydrogen matrices) versus calculated wavenumbers in the region below $1800 \mathrm{~cm}^{-1}$ to extract a global scaling factor which was applied to all the modes except the $\mathrm{OH}$ stretching modes. A second scaling factor of 0.950 was used for the $\mathrm{OH}$ stretches because of their higher anharmonicity; it was fitted to the experimental bands of the open conformers. These scaling factors take into account the average anharmonicity but reflect also the interaction between the host and the molecule. The same scaling factors were used for all the explored matrices. In comparison with experiments, no clear improvement was noticed when using anharmonic frequencies compared to the harmonic scaled ones in most of the cases. Only the latter are presented in Tables II and III. However, the anharmonic results do help in the assignments of non-fundamental bands. Anharmonic frequencies as well as additional theoretical calculations are detailed in the supplementary material. The same calculations were applied to malonaldehyde in order to compare MA and 2-ClMA. The theoretical electronic absorption (UV-Vis) spectra of enolic isomers of 2-ClMA were also obtained by solving the time-dependent DFT (TD-DFT) equations according to the method implemented in Gaussian 09.35,38-40 The five lowest triplet and five lowest singlet states were computed using the same functional and basis set, as described above.

The NCIplot software ${ }^{41,42}$ was used to perform the noncovalent interaction (NCI) study. NCI analysis allowed a clear characterization of the weak interactions at play in the systems of interest. In this case, the output was visualized with the Visual Molecular Dynamics program. ${ }^{43}$

\section{B. Experimental setup}

2-Chloromalonaldehyde was trapped in different cryogenic matrices using two different experimental devices, based on two distinct closed-cycle helium refrigerators, as 
described in our work on the CCC form. ${ }^{18}$ Briefly, one cryogenic setup (Air Products Displex DE202FF) reached the minimal temperature of $7 \mathrm{~K}$ and was used for argon and neon matrices (as described in Ref. 44). The other (ICE Oxford ICES3731) was devoted to experiments in para-hydrogen $\left(\mathrm{pH}_{2}\right)$ solids at $3 \mathrm{~K}$ and was also used for complementary experiments in neon. 2-ClMA (Acros, 95\%) was used as supplied from the manufacturer, after pumping on the reservoir tube for a few minutes at $50{ }^{\circ} \mathrm{C}$ to get rid of impurities. The low vapor pressure of this molecule is driven by the host gas flow during deposition of the samples. The guest/host ratio is estimated to be $1 / 1000$.

Vibrational spectra were obtained using an FT-IR spectrometer (Nicolet 670/870) with a resolution of $0.5 \mathrm{~cm}^{-1}$. UV absorption spectra were recorded with the first cryogenic setup using a deuterium lamp as the light source and a $0.6 \mathrm{~m}$ Jobin Yvon grating monochromator coupled to a CCD camera (Andor DH720) as a detector. The deposition window of the setup based on the Air Products Displex DE202FF (CsI in infrared studies) was changed to sapphire for the measurement of UV absorption. UV irradiations of the samples were performed with a tunable pulsed laser (Continuum Surelite II + OPO (Optical Parametric Oscillator) Horizon system, repetition rate: $10 \mathrm{~Hz}$, pulsewidth: $4 \mathrm{~ns}$ ), operating in the 200-300 nm range. The energy per pulse did not exceed $1 \mathrm{~mJ}$ on the sample.

\section{RESULTS}

\section{A. Structures and energetics of enol conformers}

The energy order for the enol and dialdehyde isomers of 2-ClMA after geometry optimization at the B3LYP/ $6-311++\mathrm{G}(3 \mathrm{df}, 3 \mathrm{dp})$ level of theory is shown in Fig. 2-only the most stable dialdehyde conformer is presented-(see
Tables S1-S4 in the supplementary material for the structural parameters of the selected conformers). ${ }^{45}$ In Fig. 2, the ZPE corrected energies of MA isomers at the same level of theory are shown in parentheses. All the enolic conformers have a planar structure. Only the dialdehyde isomer has a non-planar structure due to the $\mathrm{sp}^{3}$ hybridization of the central carbon. The substitution of the $\alpha$ hydrogen by a chlorine atom has two main consequences. First, the energies of most open conformers relative to the energy of the chelated CCC form (the most stable conformer) $-\Delta \mathrm{E}-$ decrease from MA to 2-ClMA. This effect is related to the decrease of the IHB strength in 2-ClMA compared to MA. Second, the energy order changes. It is especially modified because of an important energy decrease for CTC and TTC, which are therefore close in energy to $\mathrm{CCC}\left(\Delta \mathrm{E}=14.4 \mathrm{~kJ} \mathrm{~mol}^{-1}\right.$ and $10.1 \mathrm{~kJ} \mathrm{~mol}^{-1}$, respectively). The short distance between the chlorine atom and the hydrogen from the hydroxyl group suggests a stabilization of the CTC and TTC conformers due to the non-covalent attractive interaction between the proton and one lone electronic pair of the $\mathrm{Cl}$ atom. This is confirmed by the NCI calculations, as detailed in the supplementary material. One can also notice that the TCT-TCC conformers exchange their relative positions in 2-ClMA compared to MA, these energies being very close in both molecules.

2-ClMA isomerization is obtained through the electronic excitation of the molecule in its $\pi^{*} \leftarrow \pi$ transition of lowest energy. TD-DFT calculations were performed with the method described in Sec. II A to compute vertical energies of the $\pi^{*} \leftarrow \pi$ transition of the various enol conformers. The transition showing the highest oscillator strength is reported in Table I for each conformer and corresponds to the $\mathrm{S}_{2}-\mathrm{S}_{0}$ transition except in the case of TTT. This oscillator strength is at least one order of magnitude higher than for the other calculated transitions. The TD-DFT results of all the calculated singlet transitions are reported in Table S5 of the

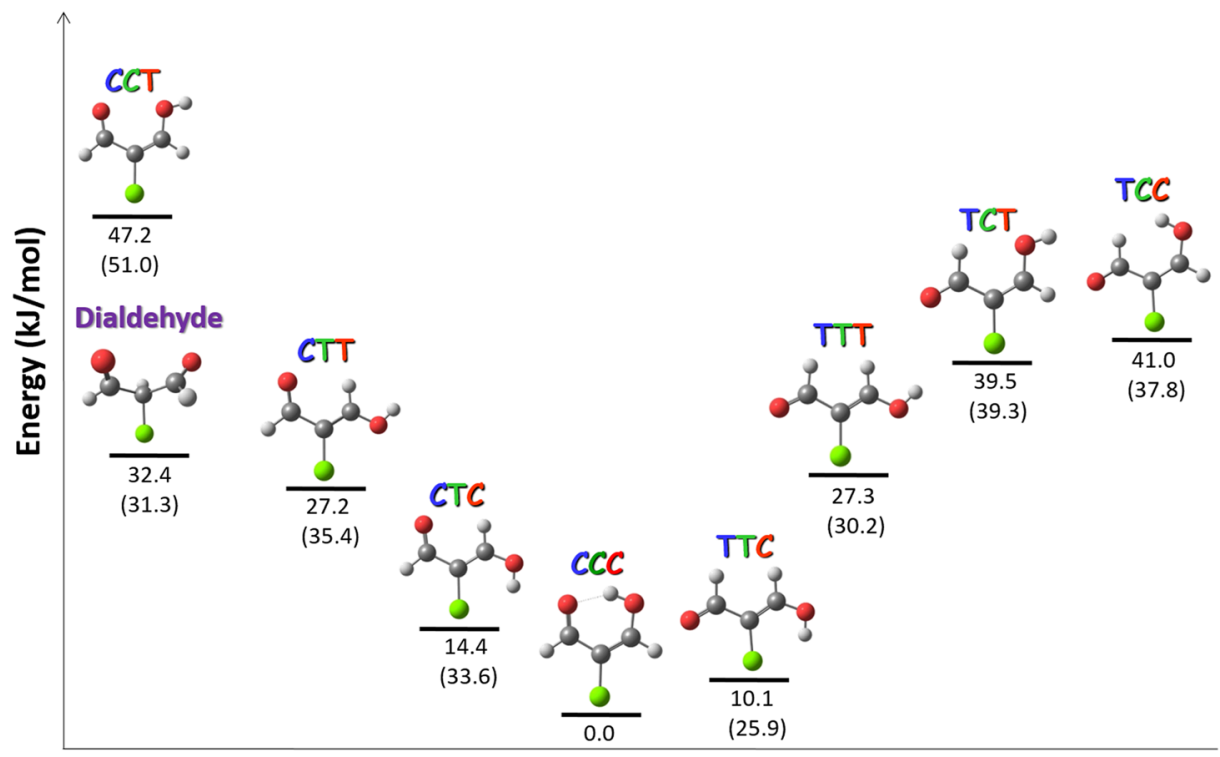

FIG. 2. Zero-point energy corrected calculated energies $\left(\Delta \mathrm{E} / \mathrm{kJ} \mathrm{mol}^{-1}\right)$ for 2 CIMA isomers (enolic isomers and most stable dialdehyde conformation) calculated at the B3LYP/6-311++G(3df,3pd) level of theory. Values in parentheses belong to the same conformers in the case of MA. 
TABLE I. TD-DFT predictions of energies and oscillator strengths for $\pi^{*} \leftarrow \pi$ electronic transitions of 2-CIMA compared with experiments, described here, and with theoretical results on MA. ${ }^{29}$ Energies in $\mathrm{eV}$ and corresponding wavelengths in $\mathrm{nm}$ in parentheses.

\begin{tabular}{llcccc}
\hline \hline Conformer & $\begin{array}{l}\text { Transition } \\
\pi^{*} \leftarrow \pi\end{array}$ & $\begin{array}{c}\text { Oscillator } \\
\text { strength (f) }\end{array}$ & $\begin{array}{c}\text { Vertical transition } \\
\text { energy }\end{array}$ & $\begin{array}{c}\text { Experimental } \\
\text { energy }\end{array}$ & $\begin{array}{c}\text { Theoretical vertical } \\
\text { energy of MA }{ }^{29}\end{array}$ \\
\hline CCC & $\mathrm{S}_{2} \leftarrow \mathrm{S}_{0}$ & 0.1091 & $4.349(285.1)$ & $\sim 4.35(285)$ & $4.81(258)$ \\
TCC & $\mathrm{S}_{2} \leftarrow \mathrm{S}_{0}$ & 0.1534 & $4.584(270.5)$ & & $5.62(221)$ \\
CCT & $\mathrm{S}_{2} \leftarrow \mathrm{S}_{0}$ & 0.1427 & $4.610(269.0)$ & & $5.60(221)$ \\
TCT & $\mathrm{S}_{2} \leftarrow \mathrm{S}_{0}$ & 0.1799 & $4.707(263.4)$ & $\sim 4.86(255)$ & $5.90(210)$ \\
CTT & $\mathrm{S}_{2} \leftarrow \mathrm{S}_{0}$ & 0.1626 & $4.713(263.1)$ & & $5.43(228)$ \\
CTC & $\mathrm{S}_{2} \leftarrow \mathrm{S}_{0}$ & 0.1753 & $4.838(256.3)$ & $\sim 4.86(255)$ & $5.46(227)$ \\
TTT & $\mathrm{S}_{3} \leftarrow \mathrm{S}_{0}$ & 0.2159 & $5.186(239.1)$ & & $6.00(207)$ \\
TTC & $\mathrm{S}_{2} \leftarrow \mathrm{S}_{0}$ & 0.2607 & $5.322(233.0)$ & $\sim 5.27(235)$ & $6.06(205)$ \\
\hline \hline
\end{tabular}

supplementary material. Theoretical predictions of the first allowed electronic transitions of MA from Ref. 29 are shown in Table I for comparison. In both molecules, the chelated form has the transition of lowest energy, as expected because of its highest degree of conjugation, and TTZ conformers have the transitions of highest energy. Of note, there is a global decrease in energy of the $\pi^{*} \leftarrow \pi$ transition from MA to 2-ClMA.

\section{B. UV-induced isomerization: Spectroscopic results}

The wavelength of the excitation laser was tuned in the spectral range of the $\pi \pi^{*}$ electronic transition in order to induce photoisomerization. This spectral range is determined experimentally by means of UV absorption spectroscopy. The production of various enol conformers of 2-CIMA was then observed following the UV irradiation of the matrices. IR and UV spectroscopies are combined to characterize the conformers. IR data combined with theoretical predictions of vibrational frequencies allow photoproduced conformers to be clearly identified.

\section{UV absorption spectra}

The UV absorption spectra were only studied for the molecule isolated in neon matrices. The matrix induced band shifts between $\mathrm{Ar}, \mathrm{Ne}$, and $\mathrm{pH}_{2}$ samples should be small, following the results on the $\pi^{*} \leftarrow \pi$ transition of MA in different matrices ${ }^{29}$ and those on a similar electronic transition of AcAc in various matrices including $\mathrm{Ar}, \mathrm{Ne}$, and $\mathrm{pH}_{2}{ }^{32,44,46}$ One can expect a slight blue shift from the argon matrix to the neon matrix, the latter generally inducing the smallest gas-to-matrix shifts.

In Fig. 3, the spectrum recorded after deposition (black) is compared to spectra obtained following a sequence of UV irradiations at various excitation wavelengths, as explained in the caption.

Two main bands are observed in the UV spectrum of the as-deposited sample. The major one, with a maximum around $285 \mathrm{~nm}$, is assigned to the $\pi-\pi^{*}$ transition in the CCC form, in perfect agreement with the theoretical prediction, as reported in Table I. The same transition for malonaldehyde is observed at $269 \mathrm{~nm}$ in argon ${ }^{29}$ and at $263 \mathrm{~nm}$ in the gas phase. ${ }^{47}$ Thus, the inclusion of the chlorine atom in the $\alpha$-position implies a bathochromic shift, as predicted theoretically (Table I). This effect has been observed and explained in dimethoxy curcuminoids compounds. ${ }^{48}$ The second band around $235 \mathrm{~nm}$ corresponds mainly to the majority open conformer detected after deposition, i.e., TTC. ${ }^{18}$ This assignment is also in perfect agreement with the theoretical predictions reported in Table I.

We have explored the effect of UV irradiation on the conformer formation with the OPO laser tuned at various wavelengths in the $230-300 \mathrm{~nm}$ spectral range. The idea was to try to optimize the production of specific conformers. The UV absorption spectrum was recorded between several of these irradiations, and examples of such spectra are shown in Fig. 3. One can remark that after some sequences of laser irradiation, the absorption profile exhibits a strong absorption between the two bands assigned to CCC and

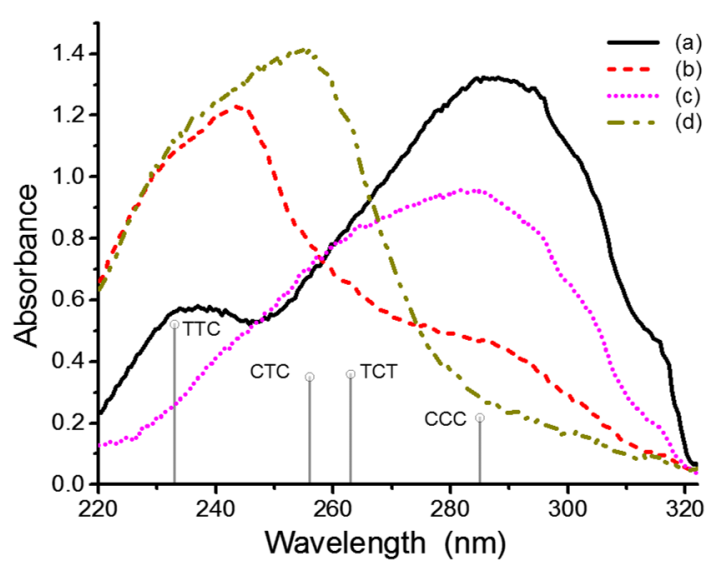

FIG. 3. UV spectra of 2-CIMA in Ne: (a) as-deposited sample (black solid line) (b) after $15^{\prime}$ irradiation at $290 \mathrm{~nm}+15^{\prime}$ irradiation at $260 \mathrm{~nm}$ (red dashed line), (c) after additional $15^{\prime}$ irradiation at $235 \mathrm{~nm}$ (pink dotted line), and (d) after additional $15^{\prime}$ irradiation at $300 \mathrm{~nm}$ (brown dashed-dotted line). The grey vertical lines are placed at the calculated $\mathrm{S}_{2} \leftarrow \mathrm{S}_{0}$ vertical transition wavelengths of the specified conformers, and their heights are proportional to the corresponding oscillator strengths. 

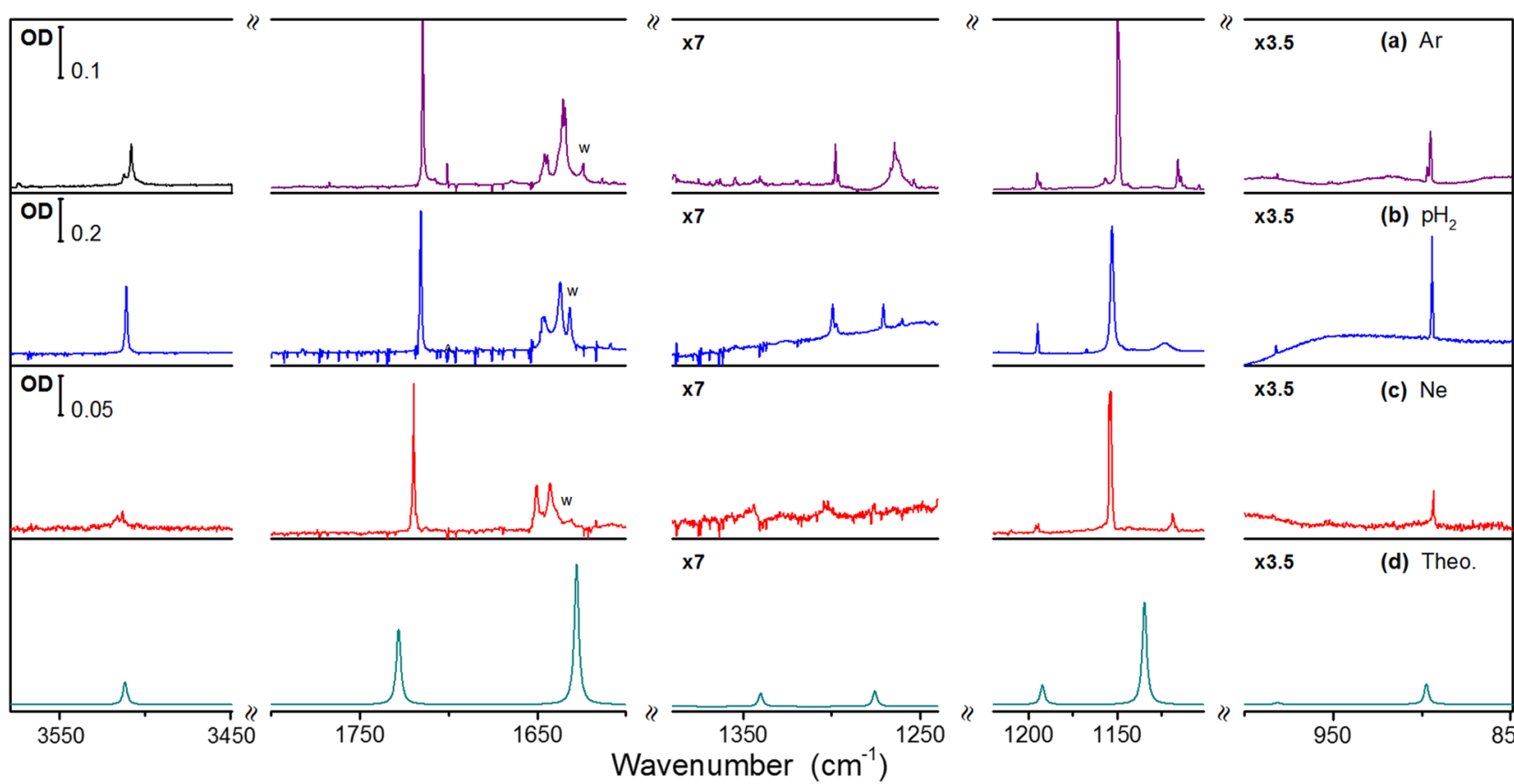

\section{Wavenumber $\left(\mathrm{cm}^{-1}\right)$}

FIG. 4. Experimental spectra of $\mathrm{TTC}$ in (a) $\mathrm{Ar}$, (b) $\mathrm{pH}_{2}$, and (c) Ne matrices. The spectra are the result of subtractions of spectra after different irradiations in order to remove bands from other conformers. (d) Calculated wavenumbers and intensities (arbitrary units) of the TTC conformer in harmonic approximation with 0.950 scaling factor in the left panel and 0.976 scaling factor in the other spectral ranges, a Lorentzian profile of FWHM $=2 \mathrm{~cm}^{-1}$ is used (w: water bands).

TABLE II. IR band positions ( $\mathrm{cm}^{-1}$ ) of TTC in $\mathrm{Ne}$, $\mathrm{pH}_{2}$, and Ar matrices, compared with scaled harmonic calculated wavenumbers (a scaling factor of 0.976 for all modes except $\mathrm{OH}$ stretching for which a scaling factor of 0.950 is applied). Calculated $\mathrm{IR}$ intensities in $\mathrm{km} / \mathrm{mol}$. Values in bold correspond to bands present in the spectra of the as-deposited samples.

\begin{tabular}{|c|c|c|c|c|c|}
\hline & & & Calculat & & \\
\hline & rimental & & & $\mathrm{T}^{\mathrm{r}}$ & \\
\hline $\mathrm{Ne}$ & $p \mathrm{H}_{2}$ & $\mathrm{Ar}$ & Mode description ${ }^{\mathrm{b}}$ & $\tilde{v}\left(\mathrm{~cm}^{-1}\right)$ & IR int. \\
\hline 3516|3512.9 & 3511 & 3508.4 & $v \mathrm{OH}$ & 3511.5 & 71 \\
\hline & 3080 & & $v \mathrm{C}_{3} \mathrm{H}$ & 3126.0 & 2 \\
\hline 2840.2 & $2827^{\mathrm{C}}$ & 2838.5 & $v \mathrm{C}_{1} \mathrm{H}^{\mathrm{d}}$ & 2824.6 & 77 \\
\hline 2823 & $2802^{c}$ & 2821 & $2^{*} \delta \mathrm{C}_{1} \mathrm{H}^{\mathrm{d}}$ & & \\
\hline 1719.7 & 1715.6 & 1714.7 & $v \mathrm{C}=\mathrm{O}$ & 1728.2 & 232 \\
\hline 1650.5 & 1646.2 & 1645.0 & Fermi $^{\mathrm{e}}$ & & \\
\hline 1642.7 & 1637.0 & 1635.2 & $v \mathrm{C}=\mathrm{C}^{\mathrm{e}}$ & 1627.7 & 430 \\
\hline & 1299.4 & 1297.9 & $\delta \mathrm{OH}+\delta \mathrm{C}_{1} \mathrm{H}+\delta \mathrm{C}_{3} \mathrm{H}$ & 1340.0 & 6 \\
\hline & 1270.7 & 1264.6 & $\delta \mathrm{C}_{3} \mathrm{H}+\delta \mathrm{OH}(+v \mathrm{CCl})$ & 1275.5 & 7 \\
\hline 1195.7|1194.1 & 1194.3 & 1194.9 & $v \mathrm{C}-\mathrm{C}+\delta \mathrm{OH}$ & 1192.0 & 60 \\
\hline 1154.3|1153.5 & 1152.8 & 1149.6 & $\delta \mathrm{OH}+\delta \mathrm{C}_{3} \mathrm{H}+v \mathrm{C}-\mathrm{C}+v \mathrm{CCl}$ & 1134.5 & 314 \\
\hline 1119 & 1123 & 1115.8 & Combination & & \\
\hline & 981.9 & 981.3 & $\gamma \mathrm{C}_{1} \mathrm{H}(\mathrm{CO})$ & 981.1 & 2 \\
\hline 893.5 & 894.2 & 895.0 & $\gamma \mathrm{C}_{3} \mathrm{H}$ & 897.3 & 18 \\
\hline 702 & 699 & 699 & $\Delta$ & 691.4 & 11 \\
\hline
\end{tabular}

${ }^{\mathrm{a}}$ Site structures reported as value1|value2.

${ }^{b} v$ : stretching; $\delta$ : in plane bending; $\gamma$ : out of plane bending; $\Delta$ : in plane ring deformation; labeling of carbon atoms from Fig. 1.

${ }^{\mathrm{c}}$ Broad features, tentative assignment.

${ }^{d}$ Anharmonic calculations predict a Fermi resonance between $v \mathrm{C}_{1} \mathrm{H}$ and $2^{*} \delta \mathrm{C}_{1} \mathrm{H}$

${ }^{\mathrm{e}}$ Anharmonic calculations predict a Fermi resonance (see text).

${ }^{\mathrm{f}} \mathrm{No}$ clear assignment can be extracted from calculations, the overtone of $\gamma \mathrm{OH}$ is a possible assignment. 
TTC [see Fig. 3(d)]. This is the signature of the production of other open conformers. The absorption of the nonchelated forms of MA was observed in argon around $230 \mathrm{~nm}^{29}$ without evidence of separate UV bands. In comparison, the non-chelated forms of 2-ClMA produced by UV irradiation absorb at longer wavelengths, as expected, and the experiment shows several distinct bands.

The electronic spectra were assigned at each step of UV irradiation by analyzing the IR spectra recorded between two steps. However, the measurement of IR spectra before and after the record of a UV spectrum indicates that the UV broadband source slightly promotes the interconversion between conformers during the acquisition of the UV spectrum. Consequently, the composition of the samples corresponding to the recorded UV spectra was not rigorously known, but the main components were extracted. Figure 3 shows a specific sequence of irradiation with the production of samples with mainly TTC (red-dashed curve) and CCC (pink dotted line). An additional irradiation in the 290-300 $\mathrm{nm}$ range depletes the CCC form, but the IR spectrum shows a combination of CTC and TTC with a small amount of TCT. The brown spectrum (dashed-dotted line) of Fig. 3 reflects this combination. We thus obtain the maxima of absorption in Ne for a mixture of CTC and TCT around $255 \mathrm{~nm}$, in good agreement with the theoretical predictions (see Fig. 3). Experimental values of the $\pi^{*} \leftarrow \pi$ transitions are compared to the theoretical estimations in Table I for the four observed conformers, and theoretical predictions are also reported in Fig. 3 for a direct comparison. The agreement is very good, except for TCT, but its determination is less accurate because it is the least abundant conformer (see Sec. III B 2).

\section{IR spectra of open conformers}

The spectra of the as-deposited 2-ClMA in argon, parahydrogen, and neon samples are described in our previous paper which focused on the CCC form of the molecule. ${ }^{18}$ The decrease of CCC bands and the growth of other bands were monitored during UV irradiation. In a typical experiment, the UV laser irradiation started at $290 \mathrm{~nm}$, a few nanometers red shifted from the maximum absorption of the CCC form, to avoid absorption by the other conformers (see Fig. 3). After a few tens of minutes, the CCC was quite depleted and the wavelength was subsequently changed to lower values until $230 \mathrm{~nm}$. IR spectra were recorded before each change of excitation wavelength. Taking into account the different kinetics of the growing IR bands and responses to the various UV irradiation wavelengths, we were able to differentiate two groups of open conformers. Of note, the same conformers are produced in the three matrices. Comparison with calculated frequencies allowed us to identify the groups of growing bands: one group to TTC and the other group to a mixture of CTC and TCT conformers. TTC and CTC are the lowest energy open enol conformers (see Fig. 2), but the last one, TCT, is much higher in energy.

Figure 4 depicts the experimental spectra of TTC in argon, para-hydrogen, and neon matrices. The frequency calculations in the harmonic approximation are reported in Table II
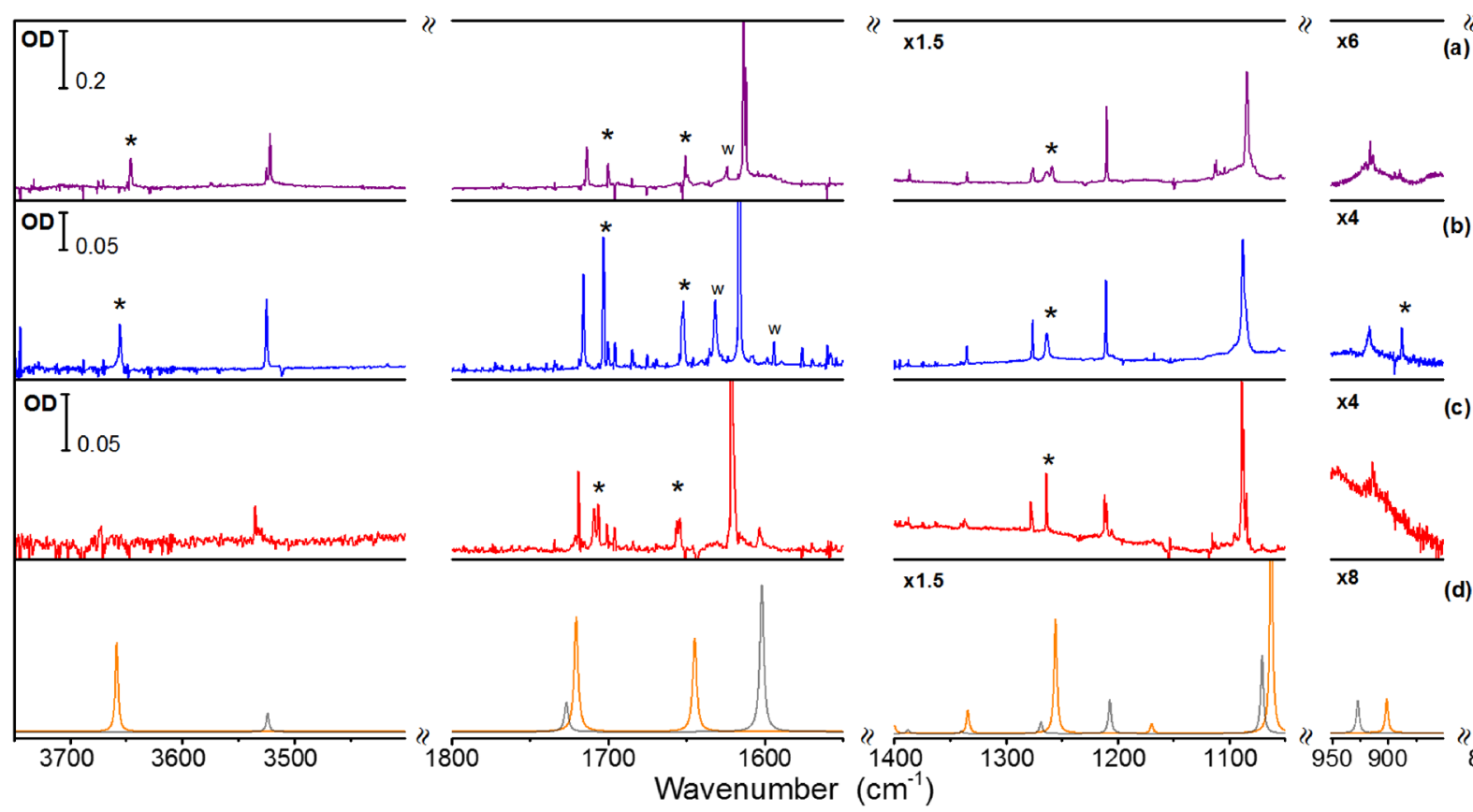

(a) $\mathrm{Ar}$
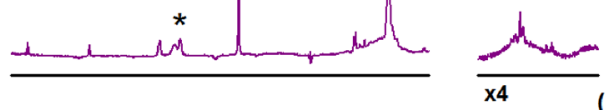

(b) $\mathrm{pH}_{2}$
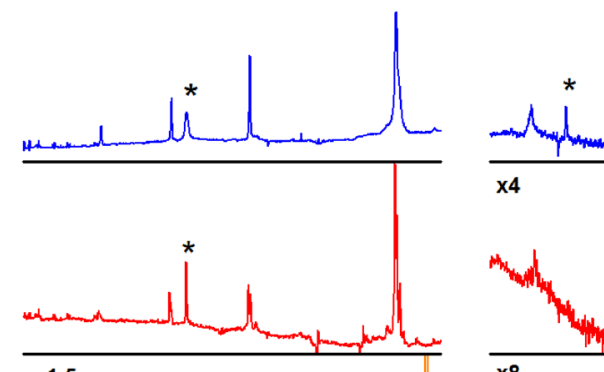

(c)
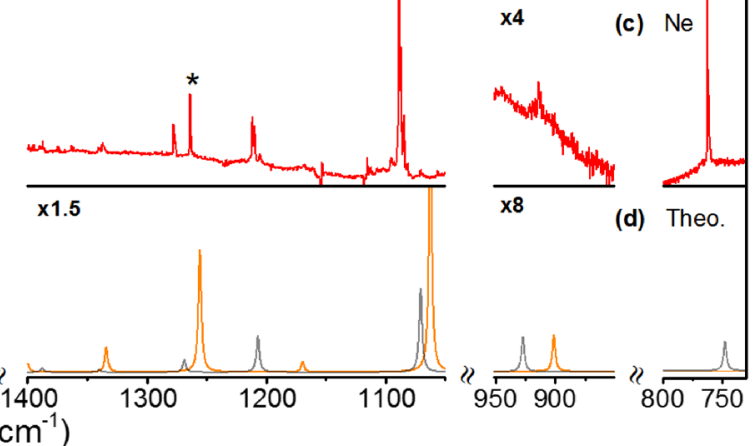

FIG. 5. Experimental spectra of CTC/TCT in (a) $\mathrm{Ar}$, (b) $\mathrm{pH}_{2}$, and (c) Ne. The spectra are the result of subtractions of spectra after different irradiations in order to remove CCC and TTC bands. Calculated spectra (a.u.) in (d) of CTC (gray line) and TCT (orange line), same conditions as in Fig. 4(d) (w: water bands and *: bands assigned to TCT). 
for comparison (all the calculated data are found in Table S7 of the supplementary material). The agreement between the calculated and experimental spectra is good, as shown in Fig. 4. As expected, only the most intense bands were observed in the as-deposited samples (values in bold given in Table II). Anharmonic frequency calculations were performed to elucidate some additional bands reflecting the possible presence of overtones or combination bands (see Table II). In particular, the band around $2800 \mathrm{~cm}^{-1}$ (not shown) is quite broad and clearly presents two components in $\mathrm{pH}_{2}$ and $\mathrm{Ne}$, and less pronounced in Ar: the $\mathrm{C}_{1}-\mathrm{H}$ (label of Fig. 1) stretch is found in Fermi resonance with the first overtone of the $\mathrm{C}_{1}-\mathrm{H}$ in-plane bending mode. A doublet is observed around $1640 \mathrm{~cm}^{-1}$ in the three matrices. Anharmonic calculations predict a Fermi resonance between the intense mode at $1627.7 \mathrm{~cm}^{-1}$ (scaled harmonic value, $\mathrm{C}=\mathrm{C}$ stretching mode) and a combination of the intense mode at $1134.5 \mathrm{~cm}^{-1}$ (scaled harmonic value, see Table II) with a low frequency mode at $482.7 \mathrm{~cm}^{-1}$ (scaled harmonic value, see Table S7).

Figure 5 shows the experimental spectra of the other group of open conformers in argon, para-hydrogen, and neon matrices. As expected, the differences in band positions between the matrices are small. The most intense band corresponds to the weak feature observed in the spectra of the as-deposited samples and is assigned to CTC. Obviously, some experimental bands do not belong to $\mathrm{CTC}$, and the comparison with theoretical predictions allows their assignment to TCT. We still obtain a similar CTC/TCT ratio in IR spectra, despite the use of different UV irradiation sequences. Using the calculated harmonic intensities of the bands around $1616 \mathrm{~cm}^{-1}$ for CTC and $1703 \mathrm{~cm}^{-1}$ for TCT, this ratio is roughly estimated to be 3 . The assignments are reported in Table III with the theoretical predictions (all the calculated data are found in Tables S8 and S9 of the supplementary material). The agreement between calculation and experiments is good. As in TTC, the band of TCT around $2850 \mathrm{~cm}^{-1}$ is broad with two components. Anharmonic calculations show again that the $\mathrm{C}_{1}-\mathrm{H}$ (label of Fig. 1) stretch is in Fermi resonance with the overtone of the $\mathrm{C}_{1}-\mathrm{H}$ in-plane bending mode. Finally, one mode of the CTC shows a structure possibly due to the isotopic effect of the chlorine. The band at $1087.5 \mathrm{~cm}^{-1}$ in $\mathrm{pH}_{2}$ presents a shoulder at $1085 \mathrm{~cm}^{-1}$, and the intensity ratio is close to 0.36 , but the calculated shift is of $0.3 \mathrm{~cm}^{-1}$ and a mode of TCT is also present. For all the other modes in the studied region, the calculations give too small isotopic shifts to be observed in our experiment; it is also the case for the TTC conformer.

The present spectroscopic study confirms the identification of TTC and CTC as the minority conformers found after deposition along with CCC. The contribution of these two conformers in the as-deposited sample was evaluated in Ref. 18 from experimental measurements, leading to slightly less than $10 \%$ for TTC and about $1 \%$ for CTC. TCT

TABLE III. CTC and TCT (italic) experimental wavenumbers $\left(\mathrm{cm}^{-1}\right)$ in Ne, $\mathrm{pH}_{2}$, and Ar matrices, compared with scaled harmonic calculated ones (a scaling factor of 0.976 for all modes except $\mathrm{OH}$ stretching for which a scaling factor of 0.950 is applied). Calculated IR intensities ( $\mathrm{km} / \mathrm{mol})$ are also reported. Values in bold correspond to bands present in the spectra of the as-deposited samples.

\begin{tabular}{|c|c|c|c|c|c|c|c|}
\hline & & & \multicolumn{5}{|c|}{ Calculations } \\
\hline \multicolumn{3}{|c|}{ Experimental $^{\mathrm{a}}$} & \multirow[b]{2}{*}{ Mode description $^{\mathrm{b}}$} & \multicolumn{2}{|c|}{ CTC } & \multicolumn{2}{|c|}{ TCT } \\
\hline $\mathrm{Ne}$ & $p \mathrm{H}_{2}$ & $\mathrm{Ar}$ & & $\tilde{v}\left(\mathrm{~cm}^{-1}\right)$ & IR int. & $\tilde{v}\left(\mathrm{~cm}^{-1}\right)$ & IR int. \\
\hline 3673 & 3655.5 & 3646.3 & $v \mathrm{OH}$ & & & 3658.3 & 173 \\
\hline \multirow[t]{3}{*}{3532} & 3524.1 & 3521.6 & $v \mathrm{OH}$ & 3523.6 & 71 & & \\
\hline & 3085.4 & 3090 & $v \mathrm{C}_{3} \mathrm{H}$ & 3139.5 & 4 & & \\
\hline & 2862.4 & $2878 \mid 2871$ & $v \mathrm{C}_{1} \mathrm{H}$ & & & 2884.8 & 41 \\
\hline 2858.5 & 2844.4 & 2858.4 & $v \mathrm{C}_{1} \mathrm{H}$ & 2865.4 & 69 & & \\
\hline 1719.0 & 1715.9 & 1713.8 & $v \mathrm{C}=\mathrm{O}$ & 1726.8 & 112 & & \\
\hline $1709 \mid 1706$ & 1702.9 & 1700.8 & $v \mathrm{C}=\mathrm{O}$ & & & 1720.4 & 223 \\
\hline $1656 \mid 1654$ & 1652 & 1650.7 & $v \mathrm{C}=\mathrm{C}$ & & & 1644.7 & 182 \\
\hline 1621.3 & 1616.1 & 1613.7 & $v \mathrm{C}=\mathrm{C}$ & 1601.8 & 563 & & \\
\hline 1387.5 & 1388 & 1386.6 & $\delta \mathrm{C}_{1} \mathrm{H}$ & 1387.9 & 9 & & \\
\hline 1336.5 & 1334.2 & 1334.4 & $\delta \mathrm{OH}\left(+\delta \mathrm{C}_{3} \mathrm{H}\right)$ & 1339.8 & 6 & & \\
\hline $1277.9 \mid 1276.6$ & 1275.7 & 1275.4 & $\delta \mathrm{C}_{3} \mathrm{H}$ & 1268.5 & 30 & & \\
\hline 1263.7 & 1263 & $1263 \mid 1258.5$ & $\delta \mathrm{OH}+v \mathrm{C}-\mathrm{O}+v \mathrm{CCl}$ & & & 1255.5 & 148 \\
\hline 1211.5|1209.7 & 1210.2 & 1209.5 & $\delta \mathrm{OH}+\delta \mathrm{C}_{3} \mathrm{H}$ & 1206.9 & 87 & & \\
\hline 1115.3 & & $1112.7 \mid 1111$ & $\delta \mathrm{OH}+v \mathrm{C}-\mathrm{O}$ & & & 1169.4 & 12 \\
\hline $1088.6 \mid \mathbf{1 0 8 7 . 1}$ & 1087.7 & 1083.7 & $\delta \mathrm{OH}+v \mathrm{C}-\mathrm{C}+v \mathrm{CCl}$ & 1070.5 & 198 & & \\
\hline 1084.4 & 1085 & 1082.6 & $v \mathrm{C}-\mathrm{O}+v \mathrm{C}-\mathrm{C}+v \mathrm{CCl}$ & & & 1062.3 & 283 \\
\hline \multirow[t]{2}{*}{913.9} & 916.3 & 916 & $\gamma \mathrm{C}_{3} \mathrm{H}$ & 927.0 & 16 & & \\
\hline & 887.5 & 889.5 & $\gamma \mathrm{C}_{3} \mathrm{H}$ & & & 901.0 & 8 \\
\hline \multirow{2}{*}{$\begin{array}{l}762.5 / 761.7 \\
708.8\end{array}$} & 760.4 & 759.6 & $\Delta$ & 747.6 & 104 & & \\
\hline & & 706.8 & $\Delta$ & & & 696.3 & 58 \\
\hline
\end{tabular}

${ }^{a}$ Site structures reported as value1|value2.

$\mathrm{b}_{v}$ : stretching; $\delta$ : in plane bending; $\gamma$ : out of plane bending; $\Delta$ : in plane ring deformation; labelling of carbon atoms from Fig. 1. 
appears in the irradiation process at the same time as CTC grows.

In $\mathrm{CCC}$, the $\mathrm{OH}$ stretching band $(\mathrm{vOH})$ is strongly redshifted and broadened because of the intramolecular hydrogen bond. It was not detected in our experiments due to its too large width. ${ }^{18}$ As expected, the $\mathrm{vOH}^{\mathrm{O}}$ bands of the open conformers appear in the spectra. The $\mathrm{OH}$ stretching spectral range clearly shows the presence of three open conformers produced by UV irradiation. TCT corresponds to the highest frequency band. CTC and TTC are red-shifted thanks to the interaction between the chlorine and the hydrogen of the hydroxyl group, and the most stabilized is the most shifted. One can remark that the influence of the matrix on the vibrational frequencies is very weak with only slightly different $v$ values in $\mathrm{Ne}, p \mathrm{H}_{2}$, and Ar [with, as "usually," $v(\mathrm{Ne})>v\left(p \mathrm{H}_{2}\right)>v(\mathrm{Ar})$ because of the increase of polarizability from $\mathrm{Ne}$ to $\mathrm{pH}_{2}$ to $\mathrm{Ar}$, even for $v \mathrm{OH}$ in TTC and CTC. The matrix influence is larger on $v \mathrm{OH}$ in TCT where the hydroxyl group is "directly" in contact with the matrix, whilst it interacts with chlorine in TTC and CTC.

Matrix effects were detected in the IR spectra of the CCC chelated form ${ }^{18}$ with vibrational bands appearing as doublets in some hosts ( $\mathrm{Ar}$ and $\mathrm{pH}_{2}$ ) and not in the other $(\mathrm{Ne})$. They are absent in the case of open conformers, as shown in Figs. 4 and 5. This observation reinforces the conclusion of Ref. 18 linking the doublets recorded in $\mathrm{Ar}$ and $\mathrm{pH}_{2}$ to the internal hydrogen bond of the CCC form.

\section{Interconversion process}

Similar irradiation sequences were performed in $\mathrm{Ar}, \mathrm{Ne}$, and $p \mathrm{H}_{2}$, leading to comparable amounts of the various conformers: identical isomerization processes should be at play in the three matrices. Figure 6 shows an example of infrared spectra resulting from a sequence of irradiation in $\mathrm{pH}_{2}$. The sequence is chosen to mimic the irradiation sequence used in Fig. 3, showing its parallel effect on the UV absorption spectrum. After deposition [panel (a)], the sample was irradiated at $290 \mathrm{~nm}$ during $20 \mathrm{~min}$. CCC almost disappeared, and the amount of open conformers increased [panel (b)]. Then, the wavelength was changed to $260 \mathrm{~nm}$, and the sample was irradiated during 20 min: (CTC, TCT) disappeared and only TTC increased [panel (c)]. Finally, we irradiated the sample at $240 \mathrm{~nm}$ for $30 \mathrm{~min}$, observing that TTC disappeared and CCC came back with traces of CTC [panel (d)].

The presented spectroscopic results highlight that the UV induced conversion process from the CCC conformer to $\mathrm{CTC} / \mathrm{TCT}$ and TTC conformers can be totally reversed by changing the irradiation wavelength to lower values $(\leq 240 \mathrm{~nm})$. It confirms that $\mathrm{CCC}$ and the various open enol conformers have well-separated electronic absorption bands. It also shows that the excited state of the open conformers can relax to the CCC ground state. Whether one conformer or the other is converted back depends on the irradiation wavelength. In the three matrices, playing with the successive UV laser irradiations, we have been able to obtain samples

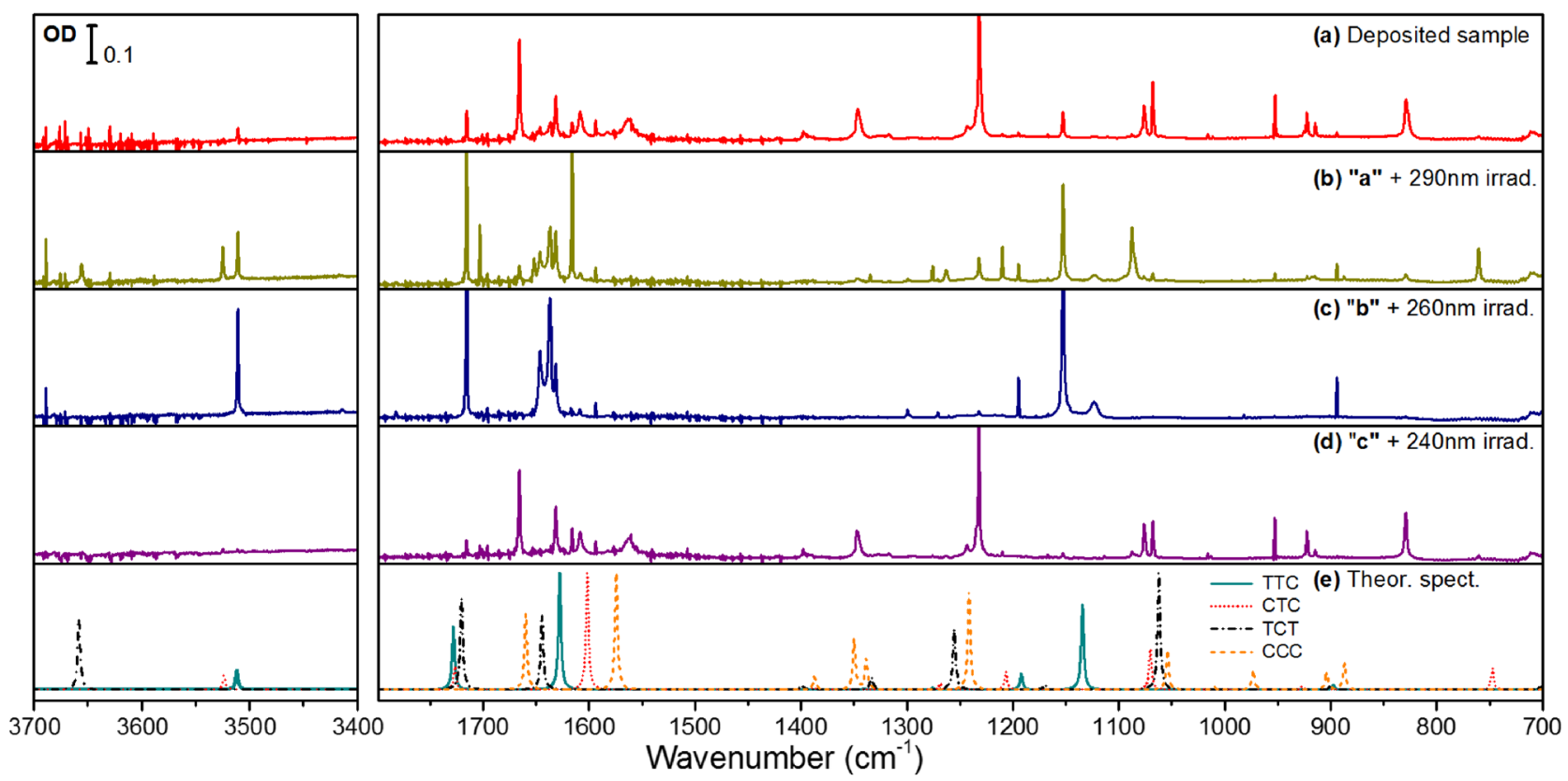

FIG. 6. Experimental FT-IR spectra 2-CIMA in the $\mathrm{pH}_{2}$ matrix: (a) deposited sample, (b) after 20 min of $290 \mathrm{~nm}$ laser irradiation, (c) previous sample after 20 min of $260 \mathrm{~nm}$ laser irradiation, (d) previous sample after $20 \mathrm{~min}$ of $240 \mathrm{~nm}$ laser irradiation, and (e) calculated spectra of CCC, TCT, CTC, and TTC conformers in harmonic approximation with 0.950 and 0.976 scaling factors for the left and the right panels, respectively. 
where only CCC or TTC prevails with less than $10 \%$ of the other conformers.

\section{DISCUSSION}

As there are few theoretical studies on 2-ClMA, those on MA can help to understand the formation of different conformers. The excited states of MA were investigated theoretically, and conical intersections between $\mathrm{S}_{0} / \mathrm{S}_{1} / \mathrm{S}_{2}$ were found explaining the efficient non-radiative process occurring after excitation in the $S_{2}$ state. ${ }^{6,10,11}$ At the triple conical intersection found by Coe and Martinez, ${ }^{10} \mathrm{MA}$ exhibits a twisted geometry with a pronounced twist around the $\mathrm{C}=\mathrm{C}$ bond. Even if the system does not reach this triple conical intersection in its electronic relaxation from $S_{2}$ to $S_{0}$, the relaxation path to $\mathrm{S}_{0}$ should involve this kind of twisted geometry as intermediates. ${ }^{11}$ In low temperature matrices, the molecule can relax in the ground state from this geometry to various minima corresponding to CCC and open conformers, especially XTZ ones. A similar photoisomerization process was discussed in the case of AcAc in matrices with open conformers resulting from the electronic relaxation of the excited CCC through several electronic states, exploring twisted geometries and leading to isomerization. ${ }^{32}$ We can assume similar isomerization paths in the case of 2-ClMA in matrices. In particular, assuming twisted intermediates similar to those of MA, the relaxation of the $\mathrm{CCC}$ form of 2-CIMA is in agreement with the production of mainly CTC and TTC in the open enol conformers.

In matrices, the UV-induced interconversions between enol conformers of MA, including back conversion to $\mathrm{CCC}$, were clearly observed by detecting the photoproduced conformers. ${ }^{24,26-29}$ Four open enol conformers of MA produced by UV irradiation were identified, namely, CTC, TTC, TCT, and TTT conformers in rare gas matrices ${ }^{24}$ and TCC, TTC, TCT, and TTT conformers in nitrogen matrices. ${ }^{28}$ In the case of 2-ClMA, only three open enol conformers (CTC, TTC, and TCT) were obtained in $\mathrm{Ar}, \mathrm{Ne}$, and $\mathrm{pH}_{2}$. A similar result was observed in acetylacetone, where only CTC, TTC, and TCC conformers were detected in $\mathrm{Ne}$ and in $\mathrm{pH}_{2}$, whereas TCT was additionally detected in normal $\mathrm{H}_{2}{ }^{34}$ and $\mathrm{Ar}^{32,33}$ matrices. It has been explained by a rapid tunneling through the $\mathrm{OH}$ rotational barrier making stable the only conformer of lower energy in each pair (XYT-XYC), this tunneling is slowed down by deuteration of the $\mathrm{H}$ of the hydroxyl group. ${ }^{44}$ We assume the same process to explain the observation of four conformers (CCC, TTC, CTC, and TCT) corresponding to the most stable conformers in each of the four pairs. In particular, it means that in 2-ClMA, TCT is more stable than TCC, in agreement with the calculations which give rather close energies for both conformers. The tunneling process occurring in (XYT$\mathrm{XYC}$ ) pairs is obviously slowed down in the case of MA in the same $\mathrm{Ar}$ and $\mathrm{Ne}$ matrices ${ }^{24,29}$ compared to 2-ClMA. It could be due to a more intrusive environment around MA, leading to an increase of the corresponding tunneling barrier. Such a hypothesis was suggested in our previous work on 2-ClMA to explain the observation of the splitting of vibrational modes in the CCC form in Ar (due to the $\mathrm{H}$-tunneling in the IHB bond), whereas no splitting were detected in the case of MA in $\mathrm{Ar}^{18}$

We were able to distinguish experimentally two groups of open conformers in 2-CIMA: CTC/TCT on one side and TTC on the other side (see Sec. III B). In the case of AcAc, the two groups were CTC on one side and TCC/TTC on the other side (with a weak amount of TTC explained by the steric problem of the two close methyl groups in TTC preventing its easy formation). ${ }^{34}$ For both molecules, these two groups are correlated with the spectral range of their respective UV absorptions. The first group (CTC/TCT in 2-ClMA and CTC in AcAc) is produced after UV irradiation in the red part of the CCC electronic spectrum, and its UV spectrum is slightly blue shifted from the CCC one, partly overlapping the latter. The second group (TTC in 2-ClMA and TCC/TTC in AcAc) has UV absorption bands of highest energy. Consequently, exciting in the red part of the CCC absorption spectrum will produce conformers of the two groups, but only those of the first group could be promoted again in the excited state and relax to other forms, whereas the second group will not be efficiently excited. In the case of AcAc, an irradiation close to the maximum of CCC absorption can destroy CTC and not TCC, increasing the amount of TCC in comparison to that of CTC. ${ }^{34}$ In the present study, the consequence is a possible selective destruction/production of various conformers when playing with a UV tunable laser. The absorption bands of CTC and TCT are theoretically separated by only $7.1 \mathrm{~nm}$, i.e., a value much smaller than the absorption bandwidths (see Fig. 3). It can explain why they cannot be separated experimentally but the constant CTC/TCT ratio resulting from various UV irradiations suggests even closer absorption bands than theoretically predicted. Besides, this constant ratio could indicate a simultaneous production of CTC and TCT in the electronic relaxation. The interconversion between CTC and TCT needs only the migration of $\mathrm{H}$ from one $\mathrm{O}$ to the other. This $\mathrm{H}$ transfer could occur during the relaxation through twisted geometries, as it was observed in the case of trifluoroacetylacetone for which the transfer from an oxygen atom to the other during UV irradiation is proved spectroscopically. ${ }^{49}$

Of note, the three open conformers were detected in the Raman spectrum of 2-ClMA/Ar samples without any UV irradiation (Raman frequencies of TTC, CTC, and TCT are reported in Tables S7, S8, and S9 in the supplementary material, respectively). ${ }^{18}$ The ratios between conformers were obviously different in the Raman and in the IR spectra of the as-deposited samples, and we concluded that the laser used for Raman spectroscopy induced photoisomerization despite its long wavelength $(785 \mathrm{~nm})$. The $\mathrm{S}_{1}-\mathrm{S}_{0}$ transition of MA was measured in the gas phase around $354 \mathrm{~nm},{ }^{50,51}$ and the state is predicted higher in energy in the case of 2-ClMA. ${ }^{17}$ Our TDDFT calculations predict a $\mathrm{S}_{1} \leftarrow \mathrm{S}_{0}$ vertical transition of the $\mathrm{CCC}$ conformer at $311.8 \mathrm{~nm}$. A two photon electronic excitation is thus highly improbable. Only remaining plausible explanation is the possibility of a vibrational excitation in the high vibrational levels of the electronic ground state. Rotamerization to TCC could be obtained from CCC with high vibrational excitation, and TCC could relax to TCT, the conformer of the lowest energy in the TCC-TCT pair. CTC could results from 
a similar rotamerization initiated in TTC, and/or by the $\mathrm{H}$ migration (detachment-recombination) previously mentioned from TCT. This deserves further studies. An important point is that, as in the case of UV isomerization, only the most stable forms of each XYT-XYC pair are detected in this experiment, in agreement with a tunneling process between the two forms of the pair, preventing the observation of the four other enol conformers in Ar.

\section{CONCLUSION}

UV irradiation of matrices doped with 2-chloromalonaldehyde breaks the internal $\mathrm{H}$ bond inducing the isomerization of the enol conformers of the molecule, as it was observed in matrix experiments with malonaldehyde (the parent molecule of the $\beta$-dialdehyde family) or $\beta$-diketones (acetylacetone and its halogenated derivatives ${ }^{49,52}$ ). Photoisomerization was detected for 2-chloromalonaldehyde isolated in the three explored cryogenic matrices $\left(\mathrm{Ar}, \mathrm{pH}_{2}\right.$, and $\mathrm{Ne}$ ) leading to the same conformers in the three environments.

This study provides new and first data on open enol conformers of a halogenated derivative of MA, the model molecule of the resonant assisted hydrogen bond in an internal $\mathrm{H}$ bond. Spectroscopic data were analyzed with the help of theoretical calculations.

Calculation results show that the substitution of a hydrogen by a chlorine atom modifies the relative energies of the different conformers and their energetic order. In particular, the relative energies of TTC and CTC conformers are especially lowered because of non-covalent interactions. This effect explains their observation as traces in the spectra of the as-deposited samples.

Eight enol conformers are predicted from calculation results, but only four of them were observed in the present experiments, including the chelated one. They correspond to the most stable form in each pair XYT-XYC. Within these four pairs, conformers differ only by the position of the $\mathrm{OH}$ group, and we assume that a tunneling process through the $\mathrm{OH}$ rotational barrier occurs to deplete the less stable form, as it was observed in acetylacetone. ${ }^{44}$ This tunneling effect is then efficient in the three matrices, whereas the tunneling process for the $\mathrm{H}$ transfer in the CCC seemed to depend strongly on the host, with an efficient quenching in Ne. ${ }^{18}$ The 2-ClMA conformers stabilized in argon are different from those of MA detected under similar experimental conditions. This confirms that guest-host interactions are sensitive to the presence of the chlorine in 2-ClMA/Ar compared to MA/Ar samples, as assumed in our previous publication focused on the $\mathrm{CCC}$ form.

Photoisomerization by means of a UV tunable laser allowed a selective production of conformers. Isomerization from chelated to non-chelated enols was observed as well as the back isomerization. Depending on the irradiation wavelength, it was possible to favor some of the conformers and to obtain separately the CCC and TTC forms. Our results provide pertinent results for a theoretical investigation of the relaxation paths from the electronically excited 2-ClMA, to be compared with studies of MA.

\section{SUPPLEMENTARY MATERIAL}

See supplementary material for the details of the conformer's optimized structures and energies, the NCI results, vertical energies of singlet-singlet transitions obtained in TD-DFT calculations, and the complete vibrational data of the eight enol conformers.

\section{ACKNOWLEDGMENTS}

We acknowledge the use of the computing center MésoLUM of the LUMAT research federation (FR LUMAT 2764). This work was supported by the RTRA Triangle de la Physique (2010-004-T NOSTADYNE and 2013-0436T REACMAQ) and by the French-Lithuanian PHC GILIBERT program (32894YA).

\section{REFERENCES}

${ }^{1}$ F. Fillaux and B. Nicolaï, Chem. Phys. Lett. 415, 357 (2005).

${ }^{2}$ V. A. Benderskii, E. V. Vetoshkina, I. S. Irgibaeva, and H. P. Trommsdorff, Chem. Phys. 262, 393 (2000).

${ }^{3}$ M. Schröder, F. Gatti, and H. D. Meyer, J. Chem. Phys. 134, 234307 (2011).

${ }^{4}$ T. Hammer and U. Manthe, J. Chem. Phys. 136, 054105 (2012).

${ }^{5}$ F. Wu, Y. Ren, and W. Bian, J. Chem. Phys. 145, 074309 (2016).

${ }^{6}$ A. L. Sobolewski and W. Domcke, J. Phys. Chem. A 103, 4494 (1999).

${ }^{7}$ A. L. Sobolewski and W. Domcke, Chem. Phys. Lett. 300, 533 (1999).

${ }^{8}$ A. L. Sobolewski and W. Domcke, Chem. Phys. 259, 181 (2000).

${ }^{9}$ J. D. Coe and T. J. Martínez, J. Am. Chem. Soc. 127, 4560 (2005).

${ }^{10}$ J. D. Coe and T. J. Martínez, J. Phys. Chem. A 110, 618 (2006).

${ }^{11}$ J. D. Coe, M. T. Ong, B. G. Levine, and T. J. Martínez, J. Phys. Chem. A 112 12559 (2008)

${ }^{12}$ J. N. Woodford, J. Phys. Chem. A 111, 8519 (2007).

${ }^{13}$ M. A. Rios and J. Rodriguez, J. Mol. Struct.: THEOCHEM 228, 149 (1990).

${ }^{14}$ Y. Nishimura, H. Ujita, and H. Sekiya, Structures and Proton Transfer of Malonaldehyde (Engineering Sciences Reports, Kyushu University, Kasuga, Fukuoka, 1993), Vol. 15, pp. 187-194.

${ }^{15}$ M. Palusiak, S. Simon, and M. Solà, Chem. Phys. 342, 43 (2007).

${ }^{16}$ E. Nakhaei and A. Nowroozi, Comput. Theor. Chem. 1096, 27 (2016).

${ }^{17}$ K. Shayan and A. Nowroozi, Struct. Chem. 27, 1769 (2016).

${ }^{18}$ A. Gutiérrez-Quintanilla, M. Chevalier, R. Platakyte, J. Ceponkus, G. RojasLorenzo, and C. Crépin, Phys. Chem. Chem. Phys. 20, 12888 (2018).

${ }^{19}$ C. Duan and D. Luckhaus, Chem. Phys. Lett. 391, 129 (2004).

${ }^{20}$ C. J. Seliskar and R. E. Hoffmann, J. Mol. Spectrosc. 96, 146 (1982).

${ }^{21}$ T. N. Wassermann, D. Luckhaus, S. Coussan, and M. A. Suhm, Phys. Chem. Chem. Phys. 8, 2344 (2006).

${ }^{22}$ N. O. B. Lüttschwager, T. N. Wassermann, S. Coussan, and M. A. Suhm, Phys. Chem. Chem. Phys. 12, 8201 (2010).

${ }^{23}$ N. O. B. Lüttschwager, T. N. Wassermann, S. Coussan, and M. A. Suhm, Mol. Phys. 111, 2211 (2013).

${ }^{24}$ T. Chiavassa, P. Verlaque, L. Pizzala, A. Allouche, and P. Roubin, J. Phys. Chem. 97, 5917 (1993).

${ }^{25}$ D. W. Firth, P. F. Barbara, and H. P. Trommsdorff, Chem. Phys. 136, 349 (1989).

${ }^{26}$ P. Roubin, T. Chiavassa, P. Verlaque, L. Pizzala, and H. Bodot, Chem. Phys. Lett. 175, 655 (1990).

${ }^{27}$ A. Trivella, Ph.D. thesis, Université de Provence, 2007.

${ }^{28}$ A. Trivella, S. Coussan, T. Chiavassa, P. Theulé, P. Roubin, and C. Manca, Low Temp. Phys. 32, 1042 (2006).

${ }^{29}$ A. Trivella, T. N. Wassermann, C. Manca Tanner, N. O. B. Lüttschwager, and S. Coussan, J. Phys. Chem. A 122, 2376 (2018). 
${ }^{30}$ S. Coussan, Y. Ferro, A. Trivella, M. Rajzmann, P. Roubin, R. Wieczorek, C. Manca, P. Piecuch, K. Kowalski, M. Włoch, S. A. Kucharski, and M. Musiał, J. Phys. Chem. A 110, 3920 (2006).

${ }^{31}$ A. Trivella, P. Roubin, P. Theulé, M. Rajzmann, S. Coussan, and C. Manca, J. Phys. Chem. A 111, 3074 (2007)

${ }^{32}$ A. Trivella, T. N. Wassermann, J. M. Mestdagh, C. M. Tanner, F. Marinelli, P. Roubin, and S. Coussan, Phys. Chem. Chem. Phys. 12, 8300 (2010).

${ }^{33}$ N. Nagashima, S. Kudoh, M. Takayanagi, and M. Nakata, J. Phys. Chem. A 105, 10832 (2001).

${ }^{34}$ R. R. Lozada-García, J. Ceponkus, M. Chevalier, W. Chin, J.-M. Mestdagh, and C. Crépin, Phys. Chem. Chem. Phys. 14, 3450 (2012).

${ }^{35}$ M. J. Frisch, G. W. Trucks, H. B. Schlegel, G. E. Scuseria, M. A. Robb, J. R. Cheeseman, G. Scalmani, V. Barone, B. Mennucci, G. A. Petersson, H. Nakatsuji, M. Caricato, X. Li, H. P. Hratchian, A. F. Izmaylov, J. Bloino, G. Zheng, J. L. Sonnenberg, M. Hada, M. Ehara, K. Toyota, R. Fukuda, J. Hasegawa, M. Ishida, T. Nakajima, Y. Honda, O. Kitao, H. Nakai, T. Vreven, J. A. Montgomery, J. E. Peralta, F. Ogliaro, M. Bearpark, J. J. Heyd, E. Brothers, K. N. Kudin, V. N. Staroverov, R. Kobayashi, J. Normand, K. Raghavachari, A. Rendell, J. C. Burant, S. S. Iyengar, J. Tomasi, M. Cossi, N. Rega, J. M. Millam, M. Klene, J. E. Knox, J. B. Cross, V. Bakken, C. Adamo, J. Jaramillo, R. Gomperts, R. E. Stratmann, O. Yazyev, A. J. Austin, R. Cammi, C. Pomelli, J. W. Ochterski, R. L. Martin, K. Morokuma, V. G. Zakrzewski, G. A. Voth, P. Salvador, J. J. Dannenberg, S. Dapprich, A. D. Daniels, O. Farkas, J. B. Foresman, J. V. Ortiz, J. Cioslowski, and D. J. Fox, Gaussian 09, Revision A.02, Gaussian, Inc., Wallingford, CT, 2009.

${ }^{36}$ A. D. Becke, J. Chem. Phys. 104, 1040 (1996).

${ }^{37}$ C. Lee, W. Yang, and R. G. Parr, Phys. Rev. B 37, 785 (1988).
${ }^{38}$ R. E. Stratmann, G. E. Scuseria, and M. J. Frisch, J. Chem. Phys. 109, 8218 (1998).

${ }^{39}$ M. E. Casida, C. Jamorski, K. C. Casida, and D. R. Salahub, J. Chem. Phys. 108, 4439 (1998).

${ }^{40}$ R. Bauernschmitt and R. Ahlrichs, Chem. Phys. Lett. 256, 454 (1996).

${ }^{41}$ J. Contreras-Garciá, E. R. Johnson, S. Keinan, R. Chaudret, J.-P. Piquemal, D. N. Beratan, and W. Yang, J. Chem. Theory Comput. 7, 625 (2011).

${ }^{42}$ E. R. Johnson, S. Keinan, P. Mori-Sanchez, J. Contreras-Garcia, A. J. Cohen, and W. Yang, J. Am. Chem. Soc. 132, 6498 (2010).

${ }^{43}$ W. Humphrey, A. Dalke, and K. Schulten, J. Mol. Graph. 14, 33 (1996).

${ }^{44} \mathrm{~A}$. Gutierrez-Quintanilla, M. Chevalier, and C. Crepin, Phys. Chem. Chem. Phys. 18, 20713 (2016).

${ }^{45}$ The energies of a few enol conformers of 2-ClMA were calculated at the M06-2X/6-11++G(3df,3dp) level of theory in Ref. 18, giving slightly lower relative energies of open conformers. The previous results obtained with the M06-2X functional are reported in the supplementary material.

${ }^{46} \mathrm{R}$. Lozada-Garcia, private communication (2012).

${ }^{47}$ C. J. Seliskar and R. E. Hoffman, Chem. Phys. Lett. 43, 481 (1976).

${ }^{48}$ P. Galer, A. Golobič, J. Koller, B. Košmrlj, and B. Sket, Chem. Cent. J. 7, 107 (2013).

${ }^{49}$ Y. Minoura, N. Nagashima, S. Kudoh, and M. Nakata, J. Phys. Chem. A 108, 2353 (2004).

${ }^{50}$ C. J. Seliskar and R. E. Hoffmann, J. Mol. Spectrosc. 88, 30 (1981).

${ }^{51}$ A. A. Arias, T. A. W. Wasserman, and P. H. Vaccaro, J. Chem. Phys. 107, 5617 (1997).

${ }^{52}$ N. Nagashima, S. Kudoh, and M. Nakata, Chem. Phys. Lett. 374, 59 (2003). 